\title{
Thoughts about Person-Centered Care for the Adult Population with Multimorbidity
}

\author{
Ming-Jye Wang1,2*, Yi-Ting Lo ${ }^{1}$ \\ ${ }^{1}$ National Taiwan University Hospital Hsin-Chu Branch, Taiwan \\ ${ }^{2}$ Department of Healthcare Management, Yuanpei University of Medical Technology, Taiwan \\ Email: *jye9129@gmail.com
}

How to cite this paper: Wang, M.-J. and Lo, Y.-T. (2016) Thoughts about PersonCentered Care for the Adult Population with Multimorbidity. Health, 8, 1275-1287. http://dx.doi.org/10.4236/health.2016.812130

Received: September 2, 2016

Accepted: September 25, 2016

Published: September 28, 2016

Copyright $\odot 2016$ by authors and Scientific Research Publishing Inc. This work is licensed under the Creative Commons Attribution International License (CC BY 4.0).

http://creativecommons.org/licenses/by/4.0/ (c) (i) Open Access

\begin{abstract}
Patients with multimorbidity are becoming the norm rather than the exception. The management of patients with several chronic diseases is now the most important challenge facing health care systems in developed countries. Based on the actual medical records of ambulatory care visits, this study investigated the prevalence and patterns of multimorbidity in 55 and older population. Among a cohort comprised of 300,000 beneficiaries selected randomly from the National Health Insurance Research Database of Taiwan in 2001, 42,441 were eligible. These were followed longitudinally 10 years. The prevalence of chronic disease rose from $62.3 \%$ to $79.8 \%$ and multimorbidity rose from $57.4 \%$ to $75.7 \%$. Multimorbidity patterns were found fell into four clusters: metabolic diseases, cardiac diseases, mental joints and gastrointestinal tract disorders. Hypertension and diabetes mellitus, as well as hyperplasia of the prostate in men, were the most common chronic diseases. The prevalence of chronic disease increased with age, especially high at age 75 - 79. Thought about the health care system for an ageing society is necessary. Applying the concept of customer experience and strengthening people-centered management in an integrated model of health care, enhancing knowledge and skills in the long-term management of chronic disease, revising clinical guidelines and training professionals in caring for the elderly, reinforcing preventive health services, especially in men's health, modifying the materials for health education, and planning for health manpower resources will provide a better model to ensure the health care for people with multimorbidity.
\end{abstract}

\section{Keywords}

Ageing Population, Multimorbidity, Patterns of Chronic Disease, Prevalence

\section{Introduction}

Worldwide, the rapidly ageing population is a major global public health challenge to 
be faced in the 21st Century. According to the World Health Organization [1], between 2015 and 2050, the proportion of the world's population over 60 years of age will nearly double from $12 \%$ to $22 \%$. By 2050 , these older adults will outnumber all children under the age of 14. In Taiwan, the proportion of the population aged 65 and over will account for $20.1 \%$ of the total population by 2025 , and up to $36.9 \%$ by 2050 [2]. One consequence of the dramatic increase in the elderly population has been that patterns of disease have changed, and this has resulted in the need for more complex medical services. Meeting the special health service needs of the elderly is an important issue for all countries.

Ageing is associated with an exponential increase in multimorbidity [3], the presence of two or more chronic disease in one individual. Patients with multimorbidity are becoming the norm rather than the exception [4] [5]. They were also the main users of health care, as $58 \%$ of patients visiting general practices had multimorbidity, and they accounted for $78 \%$ of all consultations [5]. Additionally, the negative impact of multimorbidity on clinical outcomes includes poor functional status, high mortality rate [6] [7], reduced quality of life and survival [8] [9], as well as rising health care costs and expenditures [10] [11]. The health care system, however, remains focused on single diseases in terms of medical research, training and care. Care for patients with single diseases is not always suitable for the care of patients with multimorbidity [12] [13]. Ignoring the existence of multimorbidity, and applying guidelines for the diagnosis and treatment of only a single disease may cause harm to the patient [14]. Problems with insufficient coordination of care result in ineffective, inadequate and unsafe health care and generate dissatisfaction among patients and physicians [15]. The management of patients with several chronic diseases is now the most important challenge facing health care systems in developed countries [16].

The current design of the medical care system is oriented mainly toward acute care. With the rapid ageing of the population, this will require the transformation of health care systems away from disease-based curative models and towards the provision of older-person-centered and integrated care. Medical outcomes need to be considered throughout the course of treatment. This usually involves multiple professional interventions from diagnosis and treatment to the sustainable management of patients [17]. The best way to face these challenges is to identify realistic priorities in prevention and care in terms of age and gender-related changes in the patterns of multimorbidity in older adults. In previous studies, results about multimorbidity varied widely because of the geographic setting, study population, recruitment methods, sample size, data collection, and the operational definition of multimorbidity [18]. This study utilized data drawn from the National Health Insurance database, which avoided subjective bias, and used a person-based longitudinal analysis to investigate the trend in patterns of chronic conditions in a population aged 55 and over, over a period of 10 years.

The aims of this study were: 1 ) to investigate the trends in chronic diseases and the distribution of multimorbidity in the older adult population; 2) to examine the patterns of multimorbidity in that population; and 3) to analyze the differences in patterns of 
multimorbidity in terms of age or gender. These findings may then influence the government in making health policy decisions, redesigning the health care system, and determining the timing of policy interventions and the priority of medical resource allocation to ensure the achievement of patient-centered care within a global health paradigm.

\section{Methods}

\subsection{Data Sources}

The data used in this study were taken from the National Health Insurance Research Database (NHIRD) which was constructed by the National Health Research Institutes (NHRI). Each year, the National Health Insurance Administration, Ministry of Health and Welfare (NHIA, MOHW) collects data from the National Health Insurance (NHI) program and sorts it into data files which include registration files and original claim data for reimbursement. These data files are de-identified by scrambling the identification codes of patients and care providers, including medical institutions/facilities and physicians, and then sent to the NHRI to make up the original files of NHIRD. The data are further scrambled before being released to researchers who wish to use the NHIRD and its data subsets. Each researcher is required to sign a user agreement declaring that she/he has no intent to attempt to obtain information that could potentially violate the privacy of patients or care providers and to acknowledge the NHIRD in their publications [19]. This study was approved by the review board of National Taiwan University Hospital, Hsin-Chu Branch.

\subsection{The Method of Sampling}

A longitudinal, person-based approach was used to investigate the trends of patterns of chronic conditions over 10 years for the 55 and older population. According to the NHIRD, a cohort of 1,000,000 beneficiaries was randomly sampled from the NHI registry of beneficiaries from March 1, 1995 to December 31, 2000 (from a total of approximately $23,753,407$ persons). Linear congruent random number generation was used to sample the cohort. Patients were followed longitudinally unless they were lost due to death or emigration; and the files were updated annually. There were no significant differences in age, gender, and expense distribution between the sample and the entire population [20].

\subsection{Study Participants}

The subjects analyzed in this study were 300,000 beneficiaries selected randomly from the cohort of 1,000,000. Of these, 42,441 were 55 years and older. These were followed longitudinally for multimorbidity from 2001 to 2011.

\subsection{Study Variables}

In order to investigate the elderly population suffering from chronic diseases, the following variables were included. 
Demographics: Due to the limitations of the database, the only two demographic variables that were analyzed were age and gender. Age was stratified into the following groups: 55 - 59, 60 - 64, 65 - 69, $70-74,75-79,80-84$, and 85+ for analysis.

Inclusion criteria for chronic diseases were: 1) a primary diagnosis from the International Classification of Diseases, Ninth Revision, Clinical Modification, which fell within the scope of chronic diseases covered by national health insurance; 2) at least 14 days of prescription drug use as an outpatient and two or more visits per year.

Multimorbidity referred to the presence of two or more chronic diseases in one individual.

\subsection{Statistical Analysis}

Descriptive statistics such as percentage and frequency were used to investigate the distribution of study participant characteristics, the trends in chronic disease, and the distribution of multimorbidity. Factor analysis was used to analyze the multimorbidity patterns. Logistic regression and multiple regression were used to analyze the differences in multimorbidity patterns by age and gender. Statistical significance was set at $\mathrm{p}$ $\leq 0.05$. SPSS 19.0 was used for all analyses.

\section{Results}

\subsection{Study Participant Characteristics}

Of the 42,441 study participants, $49.6 \%$ were male and $50.3 \%$ were female; the gender of 43 persons was unknown. The 55 - 64 age group accounted for $43.0 \%$; the 65 - 79 age group accounted for $47.3 \%$; and those aged $\geq 80$ accounted for $9.7 \%$. The overall prevalence of chronic disease was $62.3 \%$ (Table 1 ).

\subsection{Distribution of the Top 10 Chronic Diseases}

Among the patients with chronic diseases, those with 3 accounted for $20.1 \%$ in 2001, $19.4 \%$ in 2006 , and $18.7 \%$ in 2011 . The overall prevalence of chronic disease was $62.3 \%$ in $2001,72.1 \%$ in $2006,79.8 \%$ in 2011 , and the prevalence of multimorbidity was $57.4 \%$, $67.4 \%, 75.7 \%$, respectively (Table 2 ).

\subsection{Distribution of the Top 10 Patterns of Chronic Disease}

Hypertension (ICD-9 code 401) and diabetes mellitus (ICD-9 code 250) were the first and second most common chronic diseases in all three groups (men, women, and all patients) in 2001, 2006, and 2011, except that hyperplasia of the prostate (ICD-9 code 600) was the second most common in men in 2011. Disorders of lipid metabolism (ICD-9 code 272) were the third most common chronic disease in women and in all patients in 2006 and 2011; the next most common chronic disease was osteoarthrosis disorders (ICD-9 code 715). For men, both of these diseases increased over the 10 year period. Hyperplasia of the prostate rose from number 4 up to number 2 for men over the 10 years. Factor analysis showed that these diseases fell into four clusters: metabolic 
Table 1. Study participant characteristics.

\begin{tabular}{ccc}
\hline Variables & No. & $\%$ \\
\hline Sex & 21,031 & \\
Male & 21,367 & 49.6 \\
Female & 43 & 50.3 \\
Unknown & & 0.1 \\
Age & 8904 & \\
$55-59$ & 9327 & 21.0 \\
$60-64$ & 7946 & 22.0 \\
$65-69$ & 7200 & 18.7 \\
$70-74$ & 4942 & 17.0 \\
$75-79$ & 2597 & 11.6 \\
$80-84$ & 1525 & 6.1 \\
$85+$ & 42,441 & 3.6 \\
All patients & & 100 \\
Chronic condition & 26,431 & 62.3 \\
Yes & 16,010 & 37.7 \\
\hline
\end{tabular}

Table 2. Distribution of the top 10 chronic diseases.

\begin{tabular}{cccc}
\hline \multirow{2}{*}{ No of chronic disease } & 2001 & 2006 & 2011 \\
\cline { 2 - 4 } 1 & $\%$ & $\%$ & 5.1 \\
\hline 2 & 7.8 & 6.5 & 8.8 \\
3 & 12.9 & 11.0 & 18.7 \\
4 & 20.1 & 19.4 & 12.7 \\
5 & 14.4 & 13.8 & 12.1 \\
6 & 12.1 & 11.8 & 10.5 \\
7 & 9.4 & 10.1 & 8.1 \\
8 & 6.8 & 7.2 & 6.2 \\
9 & 5.1 & 5.7 & 4.9 \\
10 & 3.6 & 4.2 & 3.5 \\
Prevalence of chronic disease & 2.5 & 3.0 & 90.6 \\
Yccumulate (\%) & 94.7 & 92.7 & 31,240 \\
All patients & 42,441 & 36,706 & 24,931 \\
\hline (chronic disease & 26,431 & 26,464 & 79.8 \\
\hline & 57.4 & 72.1 & 67.4 \\
\hline
\end{tabular}


diseases (hypertension, diabetes, and lipid disorders); cardiac diseases (hypertensive heart disease (ICD-9 code 402) and chronic ischemic disease (ICD-9 code 414)); mental joints (osteoarthrosis disorders, general symptom (ICD-9 code 780), and neurotic disorders (ICD-9 code 300)); and gastrointestinal tract disorders (functional digestive disorders (ICD-9 code 564) and functional stomach disorders (ICD-9 code 536)) (Table 3).

\subsection{Differences in Chronic Diseases by Gender and Age}

Table 4 shows that the probability of a woman having a chronic disease was 1.23 to 1.32 times that of a man from 2001 to 2011 . There was also a positive correlation with age as the likelihood for those over 60 to have a chronic disease was higher than that of those in the 55 - 59 age group; in particular, the rate in the 65 - 84 group was more than twice that in the 55 - 59 age group. The number of chronic diseases was related to gender and age, as females had more than males, and the $75-79$ age group has the most.

Table 3. Distribution of the top 10 patterns of chronic disease.

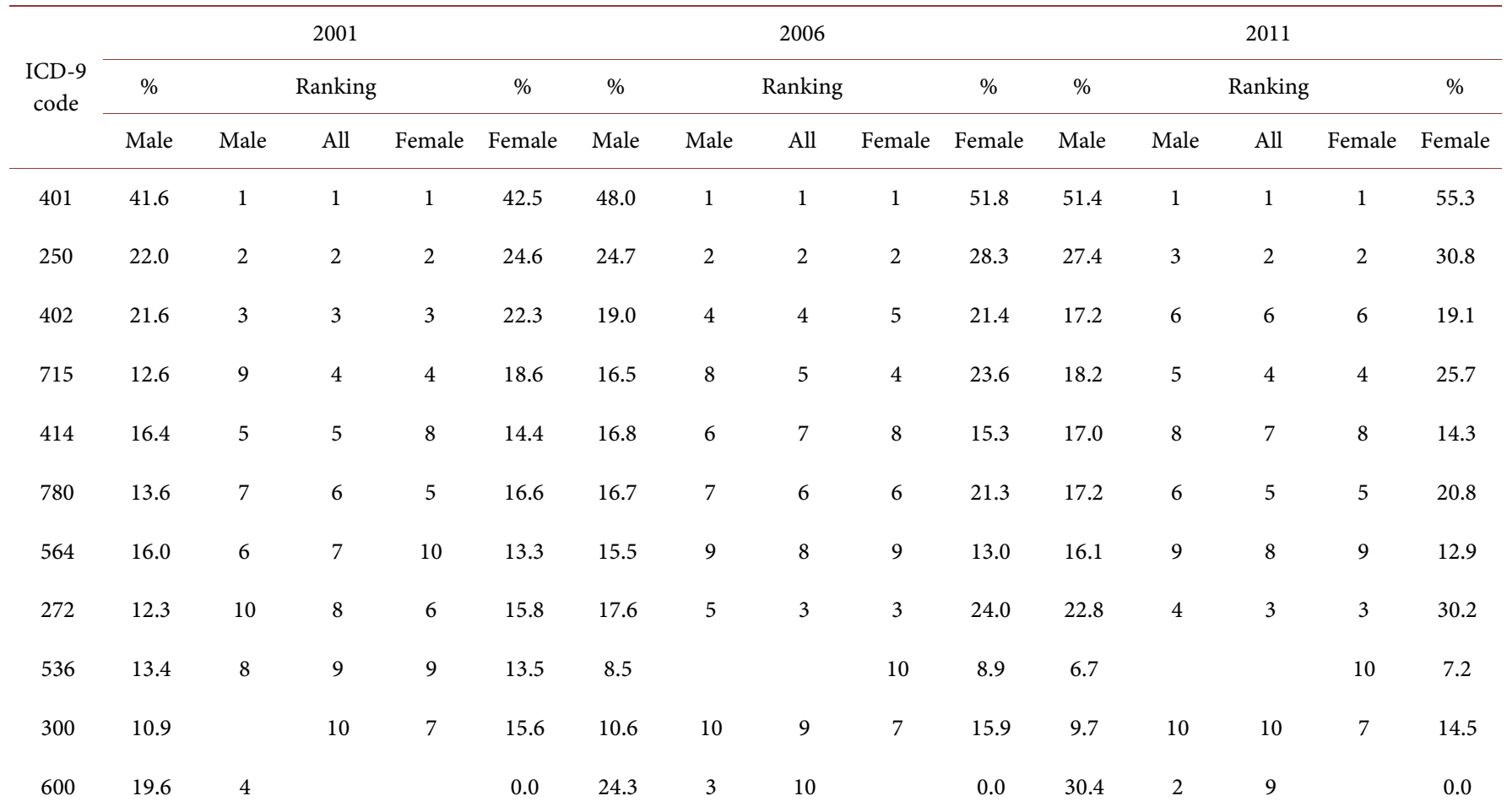

Factor analysis

Factor 1

$401,250,272$

Factor 2

Factor 3

Factor 4
402,414

$715,780,300$

564,536
$401,250,272$

402,414

$715,780,300$

564,536
250,272

$401,402,414$

$715,780,300$

564,536 
Table 4. Differences in chronic diseases by gender and age.

\begin{tabular}{|c|c|c|c|c|c|c|}
\hline \multirow{4}{*}{ Variables } & \multicolumn{3}{|c|}{ Logistic regression } & \multicolumn{3}{|c|}{ Multiple regression } \\
\hline & \multicolumn{3}{|c|}{ Yes/no chronic condition } & \multicolumn{3}{|c|}{ Dependent variables } \\
\hline & \multicolumn{3}{|c|}{ Odds ratio } & \multicolumn{3}{|c|}{ No. of chronic condition } \\
\hline & 2001 & 2006 & 2011 & 2001 & 2006 & 2011 \\
\hline (Constant) & $0.92^{* * *}$ & $1.45^{\star \star \star}$ & $2.24^{\star * *}$ & $3.90^{\star * *}$ & $4.45^{\star * *}$ & $0.52^{\star * *}$ \\
\hline \multicolumn{7}{|l|}{ Sex } \\
\hline Male & 1.00 & 1.00 & 1.00 & 0.00 & 0.00 & 0.00 \\
\hline Female & $1.23^{* * *}$ & $1.21^{\star \star \star}$ & $1.32^{\star * *}$ & $0.21^{\star \star *}$ & 0.02 & $-0.16^{\star * *}$ \\
\hline \multicolumn{7}{|l|}{ Age } \\
\hline $55-59$ & 1.00 & 1.00 & 1.00 & 0.00 & 0.00 & 0.00 \\
\hline $60-64$ & $1.30^{* * *}$ & $1.30^{\star * *}$ & $1.40^{* * *}$ & $0.38^{\star * *}$ & $0.40^{\star * *}$ & $0.36^{\star * *}$ \\
\hline $65-69$ & $1.80^{* * *}$ & $2.08^{\star * *}$ & $2.14^{\star * *}$ & $0.84^{\star * \star}$ & $0.87^{\star * *}$ & $0.82^{\star * \star}$ \\
\hline $70-74$ & $2.33^{* * *}$ & $2.60^{\star * *}$ & $2.46^{\star * *}$ & $1.30^{\star * *}$ & $1.35^{\star * *}$ & $0.98^{\star * *}$ \\
\hline $75-79$ & $2.64^{* * *}$ & $2.68^{\star * *}$ & $2.28^{\star * *}$ & $1.48^{\star * *}$ & $1.42^{* * *}$ & $0.98^{\star * *}$ \\
\hline $80-84$ & $2.42^{* * *}$ & $2.69^{\star * \star}$ & $2.08^{\star * *}$ & $1.30^{\star * *}$ & $1.14^{\star * *}$ & $0.67^{* * *}$ \\
\hline $85+$ & $1.92^{* * *}$ & $1.93^{* * *}$ & 1.36 & $1.23^{* * *}$ & $1.19^{* * *}$ & 0.38 \\
\hline
\end{tabular}

\section{Discussion}

\subsection{Summary of the Main Findings}

To the best of our knowledge, this was the first study to use a person-based longitudinal analysis to investigate the trend in patterns of chronic diseases in a population aged 55 and over, over a period of 10 years. The main findings were: The prevalence of chronic disease rose from $62.3 \%$ to $79.8 \%$ and multimorbidity rose from $57.4 \%$ to $75.7 \%$. Multimorbidity patterns were found fell into four clusters: metabolic diseases (hypertension, diabetes, and lipid disorders); cardiac diseases (hypertensive heart disease and chronic ischemic disease); mental joints (osteoarthrosis disorders, general symptom, and neurotic disorders); and gastrointestinal tract disorders (functional digestive disorders and functional stomach disorders). Hypertension and diabetes mellitus, as well as hyperplasia of the prostate in men, were the most common chronic diseases in the population aged 55 and over. Women were more susceptible to chronic diseases than were men. The prevalence of chronic disease increased with age, and was especially high among those who were 75 - 79.

\subsection{Interpretation of Results}

In this study, a 55 and older cohort was followed for 10 years, and the prevalence of chronic disease and multimorbidity grew from $62.3 \%$ to $79.8 \%$ and $57.4 \%$ to $75.7 \%$, re- 
spectively. A previous study showed that the prevalence of multimorbidity was $55 \%$ to 98\% [21], but the differences were due to methodological heterogeneity in terms of the sample size, age and recruitment of study participants, the data sources, the number of baseline diseases considered, and the statistical procedures used [22]. Schram et al. [23] investigated how settings and registry characteristics affected the prevalence of chronic disease in individuals aged 55 years and over, and found it to be $56 \%-72 \%$. Fu et al. [24] conducted a population-based study in Taiwan, and found that, among people aged 65 or older, the prevalence of chronic disease and multimorbidity was $58.3 \%$ $80.1 \%$ and $42.3 \%-64.5 \%$, respectively. The research of Chi et al. [25] was based on seniors over 65 in Taiwan, and the prevalence of chronic diseases was $70.4 \%$, which was similar to that in this study based on age. There is a clear and consistent trend towards higher prevalence rates with increasing age, and almost all studies have shown multimorbidity to be the rule rather than the exception in old age [26].

With regard to patterns of multimorbidity, the results of this study found four clusters including metabolic diseases (hypertension, diabetes, and lipid disorders);cardiac diseases (hypertensive heart disease and chronic ischemic disease); mental joints (osteoarthrosis disorders, general symptom, and neurotic disorders); and gastrointestinal tract disorders (functional digestive disorders and functional stomach disorders). Despite the methodological variability among studies, the review by Prados-Torres et al. [22] showed relevant similarities for three clusters, including a combination of cardiovascular and metabolic diseases, mental health problems, and musculoskeletal disorders. Garin et al. [27] indicated that several patterns were identified in several countries: cardio-respiratory, metabolic, and mental-articular, which were also found in this study. Our finding that hypertension and diabetes were the most common chronic diseases was consistent with most other research [25] [27]-[31].

Disorders of lipid metabolism and osteoarthrosis disorders accompanied by hypertension and diabetes were the most common chronic disease cluster in women and in all patients. Schram et al. [23] indicated that hypertension in combination with osteoarthritis, disorders of lipid metabolism, and diabetes dominated in general practice settings. Patients over 65 years of age have a high prevalence of hyper-lipidemia, and dyslipidemia of aging is becoming more prominent in women than in men. a possible explanation for the increase in lipid abnormalities in elderly women is that with advancing age and menopause, the levels of high-density lipoprotein cholesterol decrease [32]. On the basis of the radiographic criteria for osteoarthritis, the prevalence of the disease increases dramatically among persons older than 50 . This is probably because of age-related alterations in collagen and proteoglycans that decrease the tensile strength of the joint cartilage and because of a diminished nutrient supply to the cartilage. In individuals older than 55, the prevalence of osteoarthritis is higher among women than among men [33]. The risk of osteoarthritis increases with age, and women are more likely to develop osteoarthritis [34]. Hyperplasia of the prostate was the most common chronic condition in men; this was consistent with Park [30] who studied individuals aged 65 or older who self-rated chronic conditions. 
We found a trend towards higher prevalence rates of chronic diseases with increasing age, especially among those who were 75 - 79. This was consistent with most studied [21] [28] [29] [35] [36], probably because the elderly have long-term exposure and higher susceptibility to risk factors for chronic diseases. The prevalence of multiple chronic diseases may also result from earlier and better detection. Fortin et al. [18] showed that the largest differences in the prevalence of multimorbidity were observed at age 75 in both primary care and the general population; differences of this magnitude are more likely due to biases in methodology. In this study, we used person-based longitudinal and actual medical records to analyze the trends in patterns of chronic conditions and multimorbidity. This should provide more reliable estimates than those based on cross-sectional analysis and self-reported sources of information. Analysis by age demonstrated that age 75 - 79 became critical for the highest prevalence of yes/no and number of chronic conditions. Walter-Ginzburg et al. [37] indicated that age 75 or older was not significantly related to healthcare utilization. Vegda et al. [38] and Nie et al. [39] thought that there was a decrease in utilization at $85+$. Potential explanations for the declining utilization of physicians may be that those people who survived into that age group were healthier or the patients gave up; the effect of age narrows with increasing proximity to death [40].

In agreement with findings from other studies, our findings indicated that the prevalence of chronic conditions among women was higher than that among men. Interestingly, over the 10 year period, the number of chronic diseases in men was greater than that in women. In general, women are more sensible than men, are prone to express feelings easily, and show a greater awareness of health problems and symptoms. Therefore, they often have better perceptions about their own health and suffer from non-fatal condition that can be taken care of in primary healthcare settings [41], where their chronic conditions may be detected more easily. Men often responded later to the severity of symptoms than did women [42]; they also tended to delay seeking help, were less likely to have routine checkups and necessary medical care, and dealt with health problems by waiting as long as possible before seeking help [43] [44]. For men with more complex multimorbidity, a surviving spouse may take care of them and thus increase their survival. In contrast, an older woman with multimorbidity is less likely to get care from a surviving husband [45].

\subsection{Strength and Limitations}

In this study, we conducted a person-based longitudinal analysis to investigate the trend in patterns of chronic conditions and multimorbidity in population aged 55 and over, over a 10 year period. This reflected chronic situations more accurately and thus avoided potential recall biases using other methods of data collection (e.g., questionnaires).

There are some limitations to this study. First, the demographic variables in the analyses were limited to age and gender. Other variables, such as region, income, and educational level, were not considered. Second, the subjects analyzed in this study were a 
closed study population, some of whom may have moved or died during the10 year follow-up and were not included in the statistics. Third, data were based on ICD-9 coding, and the diagnostic ability of physicians, the validity of coding, and the severity of disease were additional unknowns. Future studies might further analyze the relationship between the patterns of disease, multi-morbidity, region, and hospital level, or link to the database on mortality to identify the impact of the cause of death on medical resources.

\section{Conclusion}

Compared with the previous literature which focused on cross-sectional or self-reported past history studies, this study used a cohort of 55 and older population followed for 10 years, and actual medical records were utilized to analyze the trends in patterns of chronic conditions and multimorbidity. The results clearly demonstrated that there were gender and age differences, as women were more susceptible to developing chronic diseases, and there was a trend towards higher prevalence rates for multimorbility with increasing age, especially among those who were 75 - 79. Hypertension and diabetes mellitus, and hyperplasia of the prostate in men, were the most common chronic diseases. Based on the patterns of multimorbidity, it is necessary to rethink the health care system in order to meet the needs of the elderly. Applying the concept of customer experience and strengthening people-centered management in an integrated model of health care, enhancing knowledge and skills in the long-term management of chronic disease, revising clinical guidelines and training professionals in caring for the elderly, reinforcing preventive health services, especially in men's health, modifying the materials for health education, and planning for health manpower resources will provide a better model for public health and medical care within a global health paradigm.

\section{Acknowledgements}

This study is based in part on data from the National Health Insurance Research Database provided by the Bureau of National Health Insurance, Department of Health and managed by National Health Research Institutes in Taiwan. The interpretation and conclusions contained herein do not represent those of Bureau of National Health Insurance, Department of Health or National Health Research Institutes.

\section{Conflict of Interest}

The authors declared no potential conflict of interest in this study.

\section{Funding}

This study was supported by grants from the National Taiwan University Hospital, Hsin-Chu Branch, (HCH103-065).

\section{References}

[1] WHO (2015) Ageing and Health. http://www.who.int/mediacentre/factsheets/fs404/en/ 
[2] National Development Council. Population Projections for Taiwan: 2016-2060. http://www.ndc.gov.tw/en/cp.aspx?n=2E5DCB04C64512CC

[3] Garin, N., Olaya, B., Perales, J., Monetal, M.V., Miret, M., Ayuso-Mateos, J.L., et al. (2014) Multimorbidity Patterns in a National Representative Sample of the Spanish Adult Population. PLoS One, 9, e84794. http://dx.doi.org/10.1371/journal.pone.0084794

[4] Fortin, M., Bravo, G., Hudon, C., Vanasse, A. and Lapointe, L. (2005) Prevalence of Multimorbidity among Adults Seen in Family Practice. The Annals of Family Medicine, 3, 223228. http://dx.doi.org/10.1370/afm.272

[5] Salisbury, C., Johnson, L., Purdy, S., Valderas, J.M. and Montgomery, A.A. (2011) Epidemiology and Impact of Multimorbidity in Primary Care: A Retrospective Cohort Study. The British Journal of General Practice, 61, e12-e21. http://dx.doi.org/10.3399/bjgp11X548929

[6] Ose, D., Miksch, A., Urban, E., Natanzon, I., Szecsenyi, J., et al. (2011) Health Related Quality of Life and Comorbidity. A Descriptive Analysis Comparing EQ-5D Dimensions of Patients in the German Disease Management Program for Type 2 Diabetes and Patients in Routine Care. BMC Health Services Research, 11, 179. http://dx.doi.org/10.1186/1472-6963-11-179

[7] Lee, T.A., Shields, A.E., Vogeli, C., Gibson, T.B., Woong-Sohn, M., et al. (2007) Mortality Rate in Veterans with Multiple Chronic Conditions. Journal of General Internal Medicine, 3, 403-407. http://dx.doi.org/10.1007/s11606-007-0277-2

[8] Dy, S.M., Pfoh, E.R., Salive, M.E. and Boyd, C.M. (2013) Health-Related Quality of Life and Functional Status Quality Indicators for Older Persons with Multiple Chronic Conditions. Journal of the American Geriatrics Society, 61, 2120-2127. http://dx.doi.org/10.1111/jgs.12555

[9] Marengoni, A., von Strauss, E., Rizzuto, D., Winblad, B. and Fratiglioni, L. (2009) The Impact of Chronic Multimorbidity and Disability on Functional Decline and Survival in Elderly Persons. A Community-Based, Longitudinal Study. Journal of Internal Medicine, 265, 288-295. http://dx.doi.org/10.1111/j.1365-2796.2008.02017.x

[10] Steiner, C.A. and Friedman, B. (2013) Hospital Utilization, Costs, and Mortality for Adults with Multiple Chronic Conditions, Nationwide Inpatient Sample, 2009. Preventing Chronic Disease, 10, 28. http://dx.doi.org/10.5888/pcd10.120292

[11] Van den Bussche, H., Schon, G., Kolonko, T., Hansen, H., Wegscheider, K., Glaeske, G., et al. (2011) Patterns of Ambulatory Medical Care Utilization in Elderly Patients with Special Reference to Chronic Diseases and Multimorbidity: Results from a Claims Data Based Observational Study in Germany. BMC Geriatrics, 11, 54. http://dx.doi.org/10.1186/1471-2318-11-54

[12] Tinetti, M.E., Fried, T.R. and Boyd, C.M. (2012) Designing Health Care for the Most Common Chronic Condition-Multimorbidity. JAMA, 307, 2493-2494. http://dx.doi.org/10.1001/jama.2012.5265

[13] Norris, S.L., High, K., Gill, T.M., Hennessy, S., Kutner, J.S., Reuben, D.B., Unützer, J. and Landefeld, C.S. (2008) Health Care for Older Americans with Multiple Chronic Conditions: A Research Agenda. JAGS, 56, 149-159. http://dx.doi.org/10.1111/j.1532-5415.2007.01530.x

[14] Boyd, C.M., Darer, J., Boult, C., Fried, L.P., Boult, L. and Wu, A.W. (2005) Clinical Practice Guidelines and Quality of Care for Older Patients with Multiple Comorbid Diseases: Implications for Pay for Performance. JAMA, 294, 716-724.

http://dx.doi.org/10.1001/jama.294.6.716

[15] Fortin, M., Dionne, J., Pinho, G., Gignac, J., Almirall, J. and Lapointe, L. (2006) Randomized Controlled Trials: Do They Have External Validity for Patients with Multiple Com- 
orbidities? The Annals of Family Medicine, 4, 104-108. http://dx.doi.org/10.1370/afm.516

[16] Salisbury, C. (2012) Multimorbidity: Redesigning Health Care for People Who Use It. Lancet, 380, 7-9. http://dx.doi.org/10.1016/S0140-6736(12)60482-6

[17] Paez, K.A., Zhao, L. and Hwang, W. (2009) Rising Out-of-Pocket Spending or Chronic Conditions: A Ten-Year Trend. Health Affairs, 28, 15-26. http://dx.doi.org/10.1377/hlthaff.28.1.15

[18] Fortin, M., Stewart, M., Poitras, M.E., Almirall, J. and Maddocks, H. (2012) A Systematic Review of Prevalence Studies on Multimorbidity: Toward a More Uniform Methodology. Annals of Family Medicine, 10, 142-151. http://dx.doi.org/10.1370/afm.1337

[19] National Health Research Institutes (2014) National Health Insurance Research Database. http://nhird.nhri.org.tw/en/index.html

[20] Wang, M.J., Yang, H.Y., Yang, C.C. and Lo, Y.T. (2014) Strategies for Transformational Change in the Health Care System: Challenges Facing an Aging Population. Journal of Health Science, 4, 79-88.

[21] Marengoni, A., et al. (2011) Aging with Multimorbidity: A Systematic Review of the Literature. Ageing Research Reviews, 10, 430-439. http://dx.doi.org/10.1016/j.arr.2011.03.003

[22] Prados-Torres, A., Calderón-Larrañaga, A., Hancco-Saavedra, J., Poblador-Plou, B. and van den Akker, M. (2014) Multimorbidity Patterns: A Systematic Review. Journal of Clinical Epidemiology, 67, 254-266. http://dx.doi.org/10.1016/j.jclinepi.2013.09.021

[23] Schram, M.T., Frijters, D., van de Lisdonk, E.H., et al. (2008) Setting and Registry Characteristics Affect the Prevalence and Nature of Multimorbidity in the Elderly. Journal of Clinical Epidemiology, 61, 1104-1112. http://dx.doi.org/10.1016/j.jclinepi.2007.11.021

[24] Fu, S., Huang, N. and Chou, Y. (2014) Trends in the Prevalence of Multiple Chronic Conditions in Taiwan from 2000 to 2010: A Population-Based Study. Patterns of Chronic Conditions, 11, Article ID: 140205.

[25] Chi, M.-J., Lee, C.-Y. and Wu, S.-C. (2011) The Prevalence of Chronic Conditions and Medical Expenditures of The elderly by Chronic Condition Indicator (CCI). Archives of Gerontology and Geriatrics, 52, 284-289. http://dx.doi.org/10.1016/j.archger.2010.04.017

[26] Schellevis, F.G. (2013) Epidemiology of Multiple Chronic Conditions: An International Perspective. Journal of Comorbidity, 3, 36-40. http://dx.doi.org/10.15256/joc.2013.3.25

[27] Garin, N., Koyanagi, A., Chatterji, S., et al. (2016) Global Multimorbidity Patterns: A CrossSectional, Population-Based, Multi-Country Study. Journals of Gerontology Series A: Biological Sciences and Medical Sciences, 71, 205-214. http://dx.doi.org/10.1093/gerona/glv128

[28] Violán, C., et al. (2014) Burden of Multimorbidity, Socioeconomic Status and Use of Health Services across Stages of Life in Urban Areas: A Cross-Sectional Study. BMC Public Health, 14, 530. http://dx.doi.org/10.1186/1471-2458-14-530

[29] Schäfer, I., et al. (2010) Multimorbidity Patterns in the Elderly: A New Approach of Disease Clustering Identifies Complex Interrelations between Chronic Conditions. PLoS ONE, 5, e15941. http://dx.doi.org/10.1371/journal.pone.0015941

[30] Park, J.M. (2014) Health Status and Health Services Utilization in Elderly Koreans. International Journal for Equity in Health, 13, 73. http://dx.doi.org/10.1186/s12939-014-0073-7

[31] Diederichs, C.P., Wellmann, J., Bartels, D.B., Ellert, U., Hoffmann, W. and Berger, K. (2012) How to Weight Chronic Diseases in Multimorbidity Indices? Development of a New Method on the Basis of Individual Data from Five Population-Based Studies. Journal of Clinical Epidemiology, 65, 679-685. http://dx.doi.org/10.1016/j.jclinepi.2011.11.006 
[32] Shao, H., Chen, L.-Q. and Xu, J. (2011) Treatment of Dyslipidemia in the Elderly. Journal of Geriatric Cardiology, 8, 55-64. http://dx.doi.org/10.3724/SP.J.1263.2011.00055

[33] Epidemiology. http://emedicine.medscape.com/article/330487-overview\#a6

[34] (2016) Risk Factors. http://www.mayoclinic.org/diseases-conditions/osteoarthritis/symptoms-causes/dxc-20198 250Risk

[35] Rushton, C.A., Green, J., Jaarsma, T., Walsh, P., Strömberg, A. and Kadam, U.T. (2015) The Challenge of Multimorbidity in Nurse Education: An International Perspective. Nurse Education Today, 35, 288-292. http://dx.doi.org/10.1016/j.nedt.2014.05.006

[36] Barnett, K., Mercer, S.W., Norbury, M., Watt, G., Wyke, S. and Guthrie, B. (2012) Epidemiology of Multimorbidity and Implications for Health Care, Research, and Medical Education: A Cross-Sectional Study. Lancet, 380, 37-43. http://dx.doi.org/10.1016/S0140-6736(12)60240-2

[37] Walter-Ginzburg, A., Chetrit, A., Medina, C., Blumstein, T., Gindin, J. and Modan, B. (2001) Physician Visits, Emergency Room Utilization, and Overnight Hospitalization in the Old-Old in Israel: The Cross sectional and Longitudinal Aging Study (CALAS). Journal of the American Geriatrics Society, 49, 549-556. http://dx.doi.org/10.1046/j.1532-5415.2001.49112.x

[38] Vegda, K., Nie, J.X., Wang, L., Tracy, C.S., Moineddin, R. and Upshur, R.E.G. (2009) Trends in Health Services Utilization, Medication Use, and Health Conditions among Older Adults: A 2-Year Retrospective Chart Review in a Primary Care Practice. BMC Health Services Research, 9, 217. http://dx.doi.org/10.1186/1472-6963-9-217

[39] Nie, J.X., Wang, L., Tracy, C.S., Moineddin, R. and Upshur, R.E. (2010) A PopulationBased Cohort Study of Ambulatory Care Service Utilization among Older Adults. Journal of Evaluation in Clinical Practice, 16, 825-831. http://dx.doi.org/10.1111/j.1365-2753.2009.01218.x

[40] Woo, J., Goggins, W., Zhang, X., Griffiths, S. and Wong, V. (2010) Aging and Utilization of Hospital Services in Hong Kong: Retrospective Cohort Study. International Journal of Public Health, 55, 201-207. http://dx.doi.org/10.1007/s00038-009-0068-0

[41] Vadla, D., et al. (2011) Differences in Healthcare Service Utilisation in Elderly, Registered in Eight Districts of Five European Countries. Scandinavian Journal of Public Health, 39, 272-279. http://dx.doi.org/10.1177/1403494811401476

[42] Juel, K. and Christensen, K. (2008) Are Men Seeking Medical Advice Too Late? Contacts to General Practitioners and Hospital Admissions in Denmark 2005. Public Health, 30, 111 113. http://dx.doi.org/10.1093/pubmed/fdm072

[43] Galdas, P.M., Cheater, F. and Marshall, P. (2005) Men and Health Help-Seeking Behaviour: Literature Review. Journal of Advanced Nursing, 49, 616-623. http://dx.doi.org/10.1111/j.1365-2648.2004.03331.x

[44] Harvard Medical School (2010) Mars vs. Venus: The Gender Gap in Health. Harvard Men's Health Watch, 14, 1-6.

[45] Rocca, W.A., Boyd, C.M., Grossardt, B., et al. (2014) Prevalence of Multimorbidity in a Geographically Defined American Population: Patterns by Age, Sex, and Race/Ethnicity. Mayo Clinic Proceedings, 89, 1336-1349. http://dx.doi.org/10.1016/j.mayocp.2014.07.010 
Submit or recommend next manuscript to SCIRP and we will provide best service for you:

Accepting pre-submission inquiries through Email, Facebook, LinkedIn, Twitter, etc. A wide selection of journals (inclusive of 9 subjects, more than 200 journals)

Providing 24-hour high-quality service

User-friendly online submission system

Fair and swift peer-review system

Efficient typesetting and proofreading procedure

Display of the result of downloads and visits, as well as the number of cited articles

Maximum dissemination of your research work

Submit your manuscript at: http://papersubmission.scirp.org/

Or contact health@scirp.org 